University of Wollongong

Research Online

Faculty of Business - Papers (Archive)

Faculty of Business and Law

2018

Moderator impact of Preferred HRM Culture on the Relationship between

Work Values on Contextual and Task Performance

Palli Mulla K A Chandrakumara

University of Wollongong, anilc@uow.edu.au

Follow this and additional works at: https://ro.uow.edu.au/buspapers

Part of the Business Commons

Research Online is the open access institutional repository for the University of Wollongong. For further information contact the UOW Library: research-pubs@uow.edu.au 


\title{
Moderator impact of Preferred HRM Culture on the Relationship between Work Values on Contextual and Task Performance
}

\author{
Abstract \\ This study examines the moderator effect of individual preferences for HRM practices on the relationship \\ between work values and contextual and task performance (CTP). The relevant literature suggests that \\ the notion of individual preferences in regard to their effect on CTP, moderator effect in particular, has \\ received scant systematic attention. The data were obtained in a sample of 356 manufacturing sector \\ employees in Sri Lanka. A three-step moderated hierarchical regression procedure was adopted to \\ examine the moderating effect of individual preferences. The results of the study supported the \\ hypotheses. Originally, work values and ethics had a direct effect on CTP. However, this effect was \\ moderated by employees' preferences for HRM practices. The evidence within this study reveals that \\ unique human resource values and their interaction with HR design choices could be considered as \\ sources that enhance performance at work. Implications for the theories of application work values, \\ individual preferences for HRM practices and performance are also discussed.

\section{Keywords} \\ impact, preferred, hrm, culture, relationship, between, work, moderator, values, performance, contextual, \\ task

\section{Disciplines} \\ Business

\section{Publication Details} \\ Chandrakumara, A. (2018). Moderator impact of Preferred HRM Culture on the Relationship between \\ Work Values on Contextual and Task Performance. International Journal of Business and Social Science, \\ 9 (8), 22-34.
}




\title{
Moderator impact of Preferred HRM Culture on the Relationship between Work Values on Contextual and Task Performance
}

\author{
Dr. Anil Chandrakumara \\ School of Management, Operation and Marketing \\ Faculty of Business \\ University of Wollongong \\ NSW 2522, Australia
}

\begin{abstract}
This study examines the moderator effect of individual preferences for HRM practices on the relationship between work values and contextual and task performance (CTP).The relevant literature suggests that the notion of individual preferences in regard to their effect on CTP, moderator effect in particular, has received scant systematic attention.The data were obtained in a sample of 356 manufacturing sector employees in Sri Lanka. A three-step moderated hierarchical regression procedure was adopted to examine the moderating effect of individual preferences. The results of the study supported the hypotheses. Originally, work values and ethics had a direct effect on CTP. However, this effect was moderated by employees' preferences for HRM practices. The evidence within this study reveals that unique human resource values and their interaction with HR design choices could be considered as sources that enhance performance at work. Implications for the theories of application work values, individual preferences for HRM practices and performance are also discussed.
\end{abstract}

Keywords: Work values, HRM Preferences, Moderator impact, Contextual and task performance

\section{Introduction}

The examination of both direct and indirect (moderator) impact of work values and human resources management practices could play a significant role in understanding and predicting behaviors and performance of individuals at work. Indeed, there has been an increasing interest in looking at the possible moderating effect of both work values and HRM cultures on behavioral and performance outcomes (e.g., Olsen, 2013; Saufi et al., 2013; Triguero et al, 2013; Warren et al., 2011; Snape and Redman, 2010; Taris \& Feij, 2001; Roe and Ester, 1999; Farh et al., 1997). The discovery of a significant moderator, through examining the interaction term, could yield new inferences and conclusions, and could enhance the generalizability of work value research(Sagie et al., (1996). Ros et al.,(1999) also stress the need for examining antecedents as well as the consequences on workvalues in order to enhance the applicability of theories of work values. More recent work suggest the study of moderating effect of individual level variables affecting organizational citizenship behavior (OCB) as a fruitful avenue to integrate psychological variables such as preferences with the models of situational influences on organizational behavior (e.g. Olsen, 2013; Triguero et al, 2013; Warren et al., 2011; Ilies et al., 2006).In particular, the notion of individual preferences in regard to their effect on OCB (e.g. Warren et al., 2011) and the interactive effect of values and preferences (e.g. Olsen, 2013), has received limited systematic attention in the organizational behaviour literature.In this study, we examine the moderating effect of individual preferences for HRM practices on the relationship between work values and ethics on contextual/citizenship and task performance (CTP) with a view to fill this knowledge gap and explore the possibilities of a broader research program that integrates cultural, psychological and situational variables affecting behavior at work. This allows us to examine not only which value orientations interact with which HRM practices to motivate employees to engage in CTP, but also to know how strongly individual and contextual attributes directly and indirectly affect CTP. Thus, the study has major implications for the theories of application of work values, HRM policy practice design choices/preferences, and individual attributes theory of CTP.

\section{Literature Review}

\section{1: Direct Effect of Work Values and Ethics on CTP}


Values and value systems can be used to understand human behavioras values have a strong motivational component as well as cognitive, affective, and behavioral components (Rokeach, 1973). Previous studies indicate that personal and cultural values impact reward preferences (Olsen, 2013); business ethics (Robertson et al., 2012); job involvement (Nyambegera et al., 2000); commitment (Sparrow and Wu, 1998); choice of careers (Costa et al., 1984), ethical behavior in the work place (Finegan, 1994), job satisfaction (Meglino et al, 1989) etc. In this study, we conceptualize contextual and task performance (CTP) as an outcome of work values orientation. The literature on work values is characterised by a plethora of definitions and structures. Based on a review of literature on work values and ethics, Sparrow et al.,(2010) identified five work ethics and values dimensions to explore links with organizational citizenship behaviour (OCB), which consisted of extrinsic values, intrinsic values, work ethics and beliefs, work norms, and work-locus of control. In this study, we use the same structure to extend our argument on work ethics and values and their interactive effect with individual preferences for HRM practices.

The ideas embedded in the concept of work ethics seem to be well related to the 'mastery-over-nature value', 'activity value' (activity 'doing' and activity 'thinking'), and 'individualistic' values identified by Kluckhohn \& Strodtbeck (1961). For example, the mastery-over-nature value explains the feeling of dominating and controlling the unpredictable environment. The mastery-oriented individuals tend to prefer formal planning and tight control in appraisal and career succession, as they don't feel comfortable with uncertain and unstructured environments (Mendonca \& Kanungo, 1990). Nyambegera et al., (2000) also found that job involvement/participation preferences are related to the activity thinking value. With regard to Protestant work ethics, Merrens and Garrett (1975) found that high Protestant ethic respondents spent more time working and producing more output than those people with a low Protestant ethic. Similarly, work beliefs have been shown to be fairly predictive of the behavior of managers and employees (Buchholz, 1977; and Dickson \& Buchholz, 1977). Certainly, work ethics and beliefs are positively related to personal satisfaction and productivity. This seems to suggest that people who hold positive work ethics and beliefs tend to engage in CTP activities.

H1: There is a positive relationship between positive work ethics and high level of CTP.

In relation to work locus of control (LOC) and behavioral and attitudinal variables, we might expect that internals would display greater involvement in CTP than what externals do because they perceive a greater control over the environment. For example, Reitz and Jewell (1979) found that LOC was significantly related to job involvement with internals. Further, internals seem to exert greater effort in their jobs demonstrating greater job satisfaction than externals (Spector, 1982), resulting in a possible increase of contextual performance.

H2: There is a positive relationship between individuals with internal locus of control and a relatively high level of CTP.

Hackman and Walton (1986) argue that individuals with a low need for growth may not recognize opportunities provided in empowered work environments, while those with a strong need for growth may respond positively to such work environments. Research findings also indicate positive relationships between extrinsic work values and job performance (Shapira and Griffith, 1990) and job satisfaction (Mottaz, 1986). Similarly, intrinsic values are found to be associated more strongly with job satisfaction than those who hold extrinsic values (Kazanas, 1978) and with organizational commitment (Putti et al., 1989). This seems to suggest that employees with high levels of growth and achievement values tend to be more actively involved in contextual performance activities than those who have lower levels of achievement and growth values. Overall, this evidence suggests that individuals with high growth and intrinsic value orientations tend to demonstrate a better CTP than those individuals with low growth and extrinsic value orientations. This led us to develop the following two hypotheses.

H3: Individuals with growth and achievement oriented work norms demonstrate a relatively high level of CTP.

H4: Individuals with high intrinsic value orientation demonstrate a relatively high level of CTP than those who hold extrinsic value orientation.

\section{2: Preferred HRM Culture as a Moderator of Work values -Performance Relationship}

The literature suggests that work ethics and values are of major significance to individuals in advanced, emerging or developing societies, so one of our approaches to work values is cultural rather than psychological. Those who take a cultural approach to work values consider work values as antecedent variables, where as those who take a psychological approach to work values consider work values to be a moderator variable. 
Although work values may have some effect on behavioral and work outcomes, some empirical evidence suggests that work outcomes are primarily influenced by the characteristics of work environment such as reward preferences (Olsen, 2013); personal traits (Ilies et al., 2006) autonomy and centralization (e.g., Cohen, 1992). Sagie at al., (1996) note that it is the researcher's perspective that determines whether work values are considered to be an antecedent or a moderator. In the HRM literature, previous research has considered cultural work values as explanatory variablesthat influence the design of HR policies and practices(Chandrakumara and Sparrow, 2004; Sparrow and Wu, 1998; Nyambegera et al., 2001). In this study, we examine whether the impact of work values on behavioral and performance outcomes is moderated by preferred HRM culture, integrating the both the cultural and the psychological approaches to behavior at work. Previous researchers have also claimed that what is needed in research in this area is to focus on variables that interact with cultural and work values, choices in organisations, and the outcomes of those choices (e.g. Schuler and Jackson, 2014; Sparrow et al.,2010). Thus, HRM culture as environmental or situational moderator might play a role in determining the effect of values on behavioral and performance outcomes. For example, an individual with a weak orientation to organizational ethics/collective work ethics may perform better under an individual performance based evaluation system. Similarly, in a situation where performance standards and behavior-reward contingencies are not clearly defined (weak HRM culture), work norms and values may bridge the gap and have a greater impact on behavior. Thus, the Weick (1996) and Sagie et al., (1996) models suggest that the impact of work values on outcomes may be influenced by environmental conditions or situations. Such work environment can determine whether the effect of work values will be smaller or absent (Taris and Feij, 2001). As such, in this study, we argue that the preferred HRM culture as a moderator variable on the relationship between work ethics and values and CTP.

H5: The interaction between work values and preferences for HRM practices has significant impact on CTP.

\section{Method}

\section{1: Sample and Procedure}

Data used in this paper were obtained from 356 employees of four multinational companies (MNCs) and four domestic companies in Sri Lanka. A number of control variables were used in the research design to minimize the impact of those on study variables, the preferred HRM culture in particular. Accordingly, the sample was selected by focusing on only one sector (manufacturing), and firms that have at least 200 employees, been in operation for more than five years and have a human resources or personnel division in the company. A total of 627 questionnaires were distributed through supervisory level executives. Depending on size of the firm, seventy to hundred and twenty five questionnaires were allocated to selected firmsso that respondents from middle-level managers to operator level employees are covered. 356 usable questionnaires were returned, representing a response rate of 56 percent. The sample consisted of 56 percent female and 44 percent male.A clear majority of respondents $(64 \%)$ were from operators and manual level employees. Seventy two percent of operator level employees had education up to G.C.E (A/L). There were $22 \%$ executive and managerial level respondents in the sample.

\section{2: Measures}

A questionnaire was used to assess work ethics and values and HRM policy-practice preferences byindividual employees, while CTP was assessed by the immediate supervisor of each employee.

\subsection{1: Preferred HRM Practices}

We used a scale used by previous researchers with some minor modifications as suggested by the HR managers or CEOs of participating companies. Accordingly, we initially prepared a list of 32 HRM items from the HRM practices typology presented initially by Schuler and Jackson (1987) and subsequently developed and adopted by Sparrow and Wu (1998); Nyambegera et al., (2000); and Chandrakumara \& Sparrow (2004). We offered these HRM practices to HR managers of participating companies and they confirmed that 29 HRM practices were relevant to their actual practices. As these practices present in a bi-polar statement (with two alternative ways of adopting the same HR practice), the scale actually presents the respondents with 58 alternative practices/choices to be considered in selecting their choices for HRM practices. As this study has some other aspects of analysis beyond the scope of this paper, researchers also wanted to make sure the use of commensurate measures of both actual and preferred HRM practices. Using a Varimax rotation with Kaiser Normalisation, we performed principal components analysis of preferences from 356 respondents and the result indicated a three-factor solution when 0.40 decision criterion was adopted. 
Accordingly, the factor 1 represents five HRM items that are closely associated with more formal and business need driven HR culture with 0.85 Cronbach alpha coefficient of internal consistency $(\alpha=0.85)$. The factor 2 consists of five HRM practices that deals with performance management practices $(\alpha=0.74)$. The third factor represents three HRM items that are associated with a diverse functional perspective on job-person fit $(\alpha=0.72)$. Table 1 presents the list of items with factor loading weights.

Table 1: Factor Solution for Preferences for HRM practices

Factor 1: Formal and Business Need Driven HR Culture (Alpha 0.85)

C1 Market rate for salaries and wages $\quad .886$

C6 Management's needs are considered in determining salary $\quad .868$

T5 Business need drive training provision/opportunities $\quad .850$

$\begin{array}{lll}\text { A4 } & \text { PA is done by the supervisor } & .717\end{array}$

J1 Company decides how to do the job $\quad .576$

Factor 2: Performance Management Practices (Alpha 0.74)

$\begin{array}{ll}\text { T3 All employees are provided with training opportunity } & .773\end{array}$

$\begin{array}{ll}\text { P2 Relatively long term HR Planning } & .735\end{array}$

A5 Performance based evaluation $\quad .653$

J3 Providing job instructions to a greater extent $\quad .647$

R1 Internal Promotion $\quad .644$

Factor 3: Diverse Functional Perspective of Job-Person Fit (Alpha 0.72)

J4 T \& D in diverse fields $\quad .780$

$\begin{array}{lll}\text { J5 Skills and task variety } & .798\end{array}$

D4 Career path is designed considering different functional area $\quad .771$

\subsection{2: Work Ethics and Values}

We used a scale developed by Sparrow et al., (2010) to measure work ethics and values for several reasons. First, it has been tested and adopted previously in the context of Sri Lankan manufacturing sector. Second, it has been developed by considering a broad range of work values and ethics scales published by previous researchers (e.g. MOW, 1987; England \&Harpaz, 1990; Ruiz-Quntanilla\& England, 1996; Buchholz, 1977; Wollack and Smith et.al., 1971; Spector, 1982; Ros et al., 1999; Furnham, 1997). The initial scale consisted of forty five items representing work norms and ethics, work values, extrinsic values, intrinsic values, and work locus of control. Using 356 responses, the scale items were factor analyzed using the same statistical procedure adopted in the analysis of HRM preferences as described above. A structure of five reliable factors with 30 items was emerged out of the analysis. They were interpreted as Growth oriented work norms $(\alpha=0.82)$, Career oriented work ethics $(\alpha=0.78)$, External locus of control $(\alpha=0.77)$; Extrinsic values $(\alpha=0.73)$; Intrinsic values $(\alpha=0.71)$. Table 2 presents shorter version of items and their factor loading.

Table 2: Rotated Component Matrix- Five Work Ethics and Values Variables

\begin{tabular}{lrl}
\hline Scale Items & \multicolumn{2}{c}{ Compo } \\
& 1 & 3 \\
\hline S5-Work enables learning new things. & .861 \\
W3-Entitled to interesting and meaningful work & .813 \\
W4- Thinking better ways to do his or her job & .683 & .795 \\
S2- One's job should give him a chance to try out new ideas. & .431 \\
S6-Human fulfilment through work.. & .650 \\
W1-Contributing to society. & .802 \\
B4- Working class should have a say. & .791 \\
T5-Hard work to overcome obstacles. & .681 \\
B3-Employees should have opportunity to participate in mgmt. & .673 \\
T6- Dependence on others. & .661 \\
T3- Following on his/her own thinking. & .659 \\
S1- Contribution to the group. & \\
\hline
\end{tabular}


T4- Independent from others.

.641

T8- Self-fulfilment through work.

B2-Board representation...

.610

S3- Working together is better.

C5- Luck in promotion ...

.503

C1-Luck matters a lot in recognition.

V4-Higher salary is the most important criteria.

V5-A good job is a well-paid job.

V2-The job that pays the most should be selected.

V3-The job that offer the most overtime should be selected.

V3-To be his or her own boss..

O4-Recognition through hard work..

T1- Chances for advancement.

V1-Job security..

V1- Work brings me social recognition..

V4- Job brings me respect.

R4-I resist change

R2- Predictable work
-Cronbach Alpha
$0.82 \quad 0.78$

0.77
.870

.799

.889

.880

.753

.632

.873

.718

.675

.672

.656

.648

.577

.540

Note: Only coefficients $>.50$ and shorter vision of items are presented. The rating scale 1-6

\subsection{3: Contextual and Task Performance Measures}

A scale to measure contextual performance was developed by selecting 10 items from Smith et al's (1983) organizational citizenship measure. Items were carefully selected from the scale of 16 items on the basis of several factors.1). It was felt appropriate to exclude some items, which are largely controlled by organizational rules and regulations. There were about five items relating to this: 'takes undeserved breaks', 'does not take unnecessary time off work', 'does not spend time in idle conversation', 'gives advance notice if unable to come to work' 'coasts towards the end of the day'. 2). It was also felt appropriate to exclude an item that is not relevant to every categories of employment in the sample. For example, 'great deal of time spent on personal phone conversation'. In addition, the selected items were seen as consistent with the contextual performance taxonomy proposed by the Borman and Motowidlo (1997). That is, volunteering, persisting, helping, and endorsing organizational objectives. Task performance was measured by using a scale developed by Goodman and Suyantek (1999) as it was appropriate to be used for different categories of employment. Supervisor-rating of CTP was adopted for collecting data on CTP. The scale was subjected to principal component analysis and the resulting structure indicatesthat there are three reliable factors: Contextual performance towards organization(CPTO) $(\alpha$ $=0.78)$, Contextual performance towards others/interpersonal relationships (CPTIR) $(\alpha=0.83)$, and task performance (TP) $(\alpha=0.89)$. The CTP items with factor loading weights are presented in Table 3. 
Table 3: Contextual and Task Performance: Factor Structure and Loading:

\begin{tabular}{llrl}
\hline \multicolumn{2}{c}{ Contextual Performance towards Organisation-CPTO (Supervisor Rating 0.78) } & \\
CPJ3 & Make innovative suggestions to improve the unit... & 0.881 & \\
CPJ2 & Offer suggestions to improve operations..... & 0.875 & \\
CPJ4 & Attend functions not required by the company & 0.571 \\
CPJ1 & Volunteers to do things not formally required by the job & 0.500
\end{tabular}

Contextual Performance towards Interpersonal Relationship-CPTIR (Supervisor Rating 0.83)

CPI1 Help others with their work when they are absent 0.863

$\begin{array}{ll}\text { CPI2 Help others when their workloads get increased } & 0.780\end{array}$

Task Performance (Supervisor Rating 0.89)

$\begin{array}{lll}\text { TPE2 Meet criteria for performance } & 0.728\end{array}$

$\begin{array}{lll}\text { TPE6 Handle tasks with proficiency } & 0.714\end{array}$

TPE1 Achieve the objectives of the job 0.649

TPE8 Perform well in the overall job as expected. 0.578

TPE3 Demonstrate expertise in all job related tasks $\quad 0.570$

TPE5 Could manage more responsibility than typically assigned 0.564

\section{Results}

\section{1: Direct Impact of Work Ethics and Values on CTP}

Table-4 shows the overall effect of the five work values and ethics orientations and demographic variables on CTP. In order to know predictive power of work values and ethics on CTP, the impact of the demographic factors was controlled in the step 2 of hierarchical multiple regression analysis.

Table-4 Multiple Regression Results of Values and Ethics on CTP

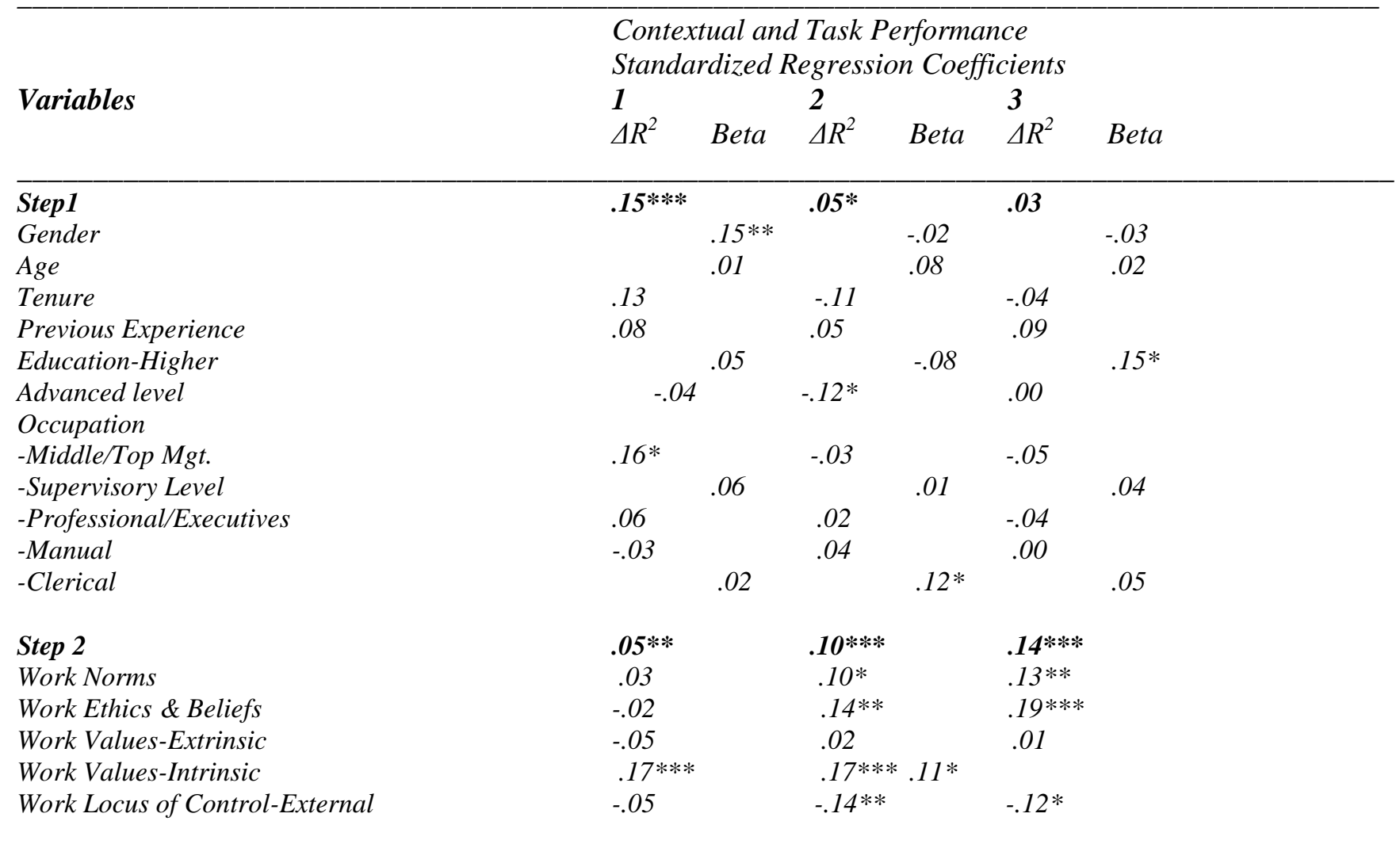

Notes- Significant Beta is shown as $P<.05^{*}, P<.01^{* *}, P<.001^{* * *} ;$ Missing data were deleted list wise.

Education \& Occupation categories were dummy coded treating ordinary level education and technical/operator category as reference groups respectively. Dependent variables 1, 2, and 3 are CPTO, CPTIR, and TP. 
Table 4 shows that demographic factors; gender $(\mathrm{P}<.01)$ and occupation $(\mathrm{P}<.05)$ in particular, account for a 15 percent variation of CPTO. However, in the overall model, the predictive power of demographic variables is significantly higher $(15-5 \%=10 \%)$ than that of for the work ethics and values variables on the CPTO. In contrast, the impact of work values on the CPTIR and TP is significantly higher (10\% and $11 \%$ respectively) than that of for the demographic variables. With regard to the impact of individual work value items, it was evident that there is a significant positive impact of work norms $(\mathrm{P}<.05)$, work ethics, $(\mathrm{P}<.01)$, and intrinsic work values $(\mathrm{P}<.001)$ on the CPTIR and a significant negative impact of external locus of control $(\mathrm{P}<.001)$ on the CPTIR. Similarly, all variables of work values and ethics, excluding extrinsic values, account for 14 percent variation of 'task performance'.

In brief, the evidence indicates that the CPTIR (10\%) and task performance (14\%) are significantly influenced by work ethics and values, while the impact of demographic factor of gender and managerial level jobs is significant on the CPTO.

\section{2: Preferred HRM Culture as a Moderator}

We adopted the three-step moderated hierarchical regression procedure suggested by Baron and Kenny (1986) and James and Brett (1984) and adopted by Farh et al., (1997) and Hu and Lee (2000). For example, in examining the moderating effect of the business driven HR culture (BDHRC) on work norms and CPTO, we first regressed the CPTO on demographic variables. The main effects of work norms and BDHRC were then added to the regression equation in step 2. In the final step of the analysis, the interaction term of work norms and BDHRC was loaded into the equation. We tested the moderating effect by examining the change in $\mathrm{R}^{2}$ attributable to the interaction term. If the interaction term added to the final stage of the regression model produces a significant $\mathrm{R}^{2}$, then BDHRC could be said to be a moderator of the relationship between work norms and CPTO. To eliminate possible multicollinearity effect between higher-order terms (interactive effect), statistically significant interactions are interpreted by considering high and low values of the moderator variables (e.g Aiken \& West, 1991). The outcome is presented in the last two column of Table 5.

Table-5 Summary of Moderated Regression Analysis: Impact of Preferred HRM Culture on the Relationship between WEV and CTP (with the results of Split Sampling Correlation Analysis)

\begin{tabular}{|c|c|c|c|c|c|c|}
\hline Variables & e Analysis & \multirow{2}{*}{$\begin{array}{c}\Delta \boldsymbol{R}^{2} \\
.01^{*}\end{array}$} & \multirow{2}{*}{$\begin{array}{l}\boldsymbol{\beta} \\
.08^{*}\end{array}$} & \multirow{2}{*}{\begin{tabular}{|l|}
$\boldsymbol{F}$ \\
$6.26^{* * * *}$
\end{tabular}} & \multirow{2}{*}{$\begin{array}{c}\text { HRM }(\text { Low }) \\
\left(\begin{array}{c}\text { scores } \leq 3) \\
r\end{array}\right. \\
-.09\end{array}$} & \multirow{2}{*}{$\begin{array}{l}\begin{array}{l}\text { HRM }(\text { High }) \\
(\text { scores }>3)\end{array} \\
\boldsymbol{r} \\
.19\end{array}$} \\
\hline 1. $C P T O$ & -Work Locus of Control $\boldsymbol{x}$ BDHRC & & & & & \\
\hline & -Extrinsic Values $\boldsymbol{x} P M P$ & $.01 *$ & $.07 *$ & $7.41 * * *$ & -.11 & -.01 \\
\hline & -Work Norms $\boldsymbol{x} J$-P fit & $.01 *$ & $.08 *$ & $6.57 * * *$ & -.35 & .19 \\
\hline & -Extrinsic Values $x$ J-P fit & $.01 *$ & $.04 *$ & $6.25 * * *$ & .29 & -.13 \\
\hline \multirow[t]{6}{*}{ 2. CPTIR } & -Extrinsic Values $\boldsymbol{x}$ BDHRC & $.05 * * *$ & $.24 * * *$ & $5.18 * * *$ & -.02 & .40 \\
\hline & -Extrinsic Values $\boldsymbol{x} P M P$ & $.04 * * *$ & $.15 * * *$ & $3.85 * * *$ & -.01 & .07 \\
\hline & -Work Norms $\boldsymbol{x}$ PMP & $.01 *$ & $.13 *$ & $3.39 * * *$ & .08 & .16 \\
\hline & -Work Norms $\boldsymbol{x} J-P$ fit & $.01 *$ & $.08 *$ & $3.17 * * *$ & -.38 & .15 \\
\hline & -Extrinsic values $\boldsymbol{x} J$-P fit & $.02 * *$ & $.06 * *$ & $2.57 * *$ & -.14 & .01 \\
\hline & -Intrinsic values $x$ J-P fit & $.01 *$ & $-.08 *$ & $3.55 * * *$ & -.08 & .08 \\
\hline \multicolumn{2}{|c|}{-Work Norms $\boldsymbol{x}$ BDHRC } & $.02 * *$ & $.21 * *$ & $5.64 * * *$ & .17 & .15 \\
\hline \multicolumn{2}{|c|}{-Extrinsic Values $\boldsymbol{x}$ BDHRC } & $.02 * *$ & $.16^{* *}$ & $5.72 * * *$ & -.10 & .42 \\
\hline \multicolumn{2}{|c|}{-Work Locus of Control $\boldsymbol{x}$ BDHRC } & $.01 * *$ & $.11 * *$ & $4.98 * * *$ & -.11 & .51 \\
\hline \multicolumn{2}{|c|}{-Work Norms $\boldsymbol{x} P M P$} & $.03 * * *$ & $.25 * * *$ & $4.71 * * *$ & .15 & .18 \\
\hline \multicolumn{2}{|c|}{-Work Norms $\boldsymbol{x} J$-P fit } & $.03 * * *$ & $.17 * * *$ & $4.07 * * *$ & -.16 & .21 \\
\hline \multicolumn{2}{|c|}{-Extrinsic values $x$ J-P fit } & $.01 *$ & $.04 *$ & $2.35 * *$ & .08 & -.10 \\
\hline
\end{tabular}


Table-5 shows that all the three preferred HRM cultures moderates the relationships between work values and CTP. The patterns of interaction were interpreted using the sign of the beta coefficients. For example, the sign of the significant beta coefficient with regards to the relationship between work locus of control (WLC) and CPTO, which is moderated by business driven HR culture (BDHRC) is positive $(\beta=.08 ; \mathrm{P}>.05)$. This indicates that the higher the score on BDHRC, the stronger the relationship between WLC and CPTO. In order to support interpretation of beta coefficients associated with the moderator effect, previous researchers (e.g., Farh et al., 1997; Hui and Lee, 2000) have performed split sampling correlation analysis for low and high denomination of scores of the moderator. According to Farh et al., (1997), split sampling correlation shows "the typical significant interaction effect" (pp: 437). Therefore, we recognize that this kind of analysis is necessary because the beta sign indicates the direction of effect when considering the scores of moderator on average.

For example, the high and low denominations of moderator (HRM practices) variables in this study are very important for practicing managers because they represent two alternative orientations to HRM practices. In addition, it is found that when the direct impact of the both the predictor and the moderator is negative, the impact of interaction terms becomes positive mathematically (the sign of beta for interaction effect), which can also be seen in the coefficient table of regression output (e.g., WLC x BDHRC impact on CPTO). In such cases, it is essential to examine the typical direction of the beta sign by performing a split sample correlation analysis in order to identify the direction of the impact for interpretive purposes. Accordingly, the last two columns of Table5 present the result of the split sampling analysis.

Overall, the findings of this study indicate that all the three HRM cultures moderate the relationship between work orientations and CTP. The HRM culture that is concerned with business driven HR practices is found to be a significant moderator of the relationship between internal work locus of control and CPTO and TP, extrinsic values and CPTIR and TP, and work norms and TP, Secondly, it was found that performance management practices significantly moderate the relationship between extrinsic values and CPTO and CPTIR, work norms and CPTIR and TP. The third HRM sub culture that is concerned with the diverse functional perspective on jobperson fit significantly moderates the relationship between work norms and CPTO, CPTIR, and TP, extrinsic work values and CPTO, CPTIR, and TP, and intrinsic work values and TP.

\section{Discussion}

\section{1: Direct impact of work values and ethics}

One of the objectives of this study is to examine the impact of work orientations on CTP. The evidence showed that that both demographic factors and work ethics and values (WEV) influenced CTP. The impact of demographic factors is relatively high for CPTO, while that of WEV is relatively high for CPTIR and TP. It was found that male employees tend to be more involved in the CPTO than female employees. Similarly, middle and higher-level managers' involvement in CTP is relatively higher than that of operator/technical level employees. In their review article, Podsakoff et al., (2000)note that there is a lack of research evidence to show the impact of such demographic variables as gender and tenure on OCB. The evidence of this study fills this knowledge gap by indicating that male employees tend to be more involved in CPTO than female employees. In addition, although comparable research evidence is scarce on the impact of employment category on CTP, this study found that the middle and higher level managers' involvement in CTP is relatively high.

The impact of education on CPTIR and TP is also evident in this study. Interestingly, it shows that when the level of education moves from a lower to a moderate level, employees tend to decrease their involvement in CPTIR. With regards to task performance, the analysis shows that the higher the level of education, the greater the involvement in task performance. Although the difference is small, there seems to be a tendency to indicate that clerical employees tend to be more interpersonally active than operator/technical level employees. The WEV variables of growth oriented work norms, career oriented work ethics, and intrinsic values significantly influenceCPTIR and TP. The only work value variable that affectCPTO is intrinsic values. This finding is consistent with the findings of previous research in which similar explanatory and outcome variables have been used (e.g., Sparrow and Wu (1998); Nyambegera at al., (2001); Yeatts \& Hyten, 1998; Hackman and Walton, 1986; England 1974). The finding of a significant negative impact of external work locus of control on CPTIR and TP, is also consistent with several previous studies (e.g., Reitz and Jewell, 1979; Motowidlo and Van Scotter (1994). In brief, the overall result indicates that all the five WEV orientations impact positively or negatively on at least one aspect of the three performance categories used in this study, and thus confirming all the hypotheses from $\mathrm{H} 1$ to $\mathrm{H} 4$. 


\section{2: Moderator impact of Preferred HRM culture}

Table-5 indicates that all the three HRM subcultures have moderating impact on the relationship between WEV and CTP. Our discussion on each of the HRM subculture is presented next.

\subsection{1: Business Driven HRM Culture as a Moderator}

First, the impact of external work locus of control on CPTO $(\beta=.08 ; \mathrm{P}<.05 ; \mathrm{r}=.19)$ and TP $(\beta=.04 ; \mathrm{P}<.05 ; \mathrm{r}=$ .29) is positive in an environment of more business driven HRM culture. This finding represents the very theoretical nature of externals who always seek directives from their supervisors, and who believe that success is a matter of good fortune. Therefore, they may feel more comfortable in a less empowered HRM culture where they do not want to take challenges and risks in order to be productively involved in CTP activities.

This finding seems to be consistent with Sparrow and Wu's (1998) finding that the stronger the relationship to 'nature-subjugation' value orientation, the more employees prefer centralized decision making, short-term planning choices, and limited worker determination of how work is carried out (the nature-subjugation value orientation is conceptually associated with external work locus of control). Second, the impact of extrinsic value orientations on CPTIR $(\beta=.24 ; \mathrm{P}<.001 ; \mathrm{r}=.40)$ and TP $(\beta=.16 ; \mathrm{P}<.01 ; \mathrm{r}=.42)$ is positive and stronger in an environment of business driven HRM culture. This may be due to the fact that individuals with extrinsic values generally expect material and monetary rewards as motivators, rather than psychological or intrinsic motivators. They also seem more comfortable in less empowered cultures to engage in productive activities in relation to CPTIR and TP. Third, the employees with individual growth oriented work norms tend to produce positive TP outcomes $(\beta=.21 ; \mathrm{P}<.01 ; \mathrm{r}=.17)$ in an environment of less business driven (as high correlation is for low HRM score) or more empowering HRM culture. This finding is consistent with Hackman and Walton (1986) assertion that the individuals with a strong need for growth should respond eagerly and positively to the opportunities provided by enriched work and also with Hackman and Lawler's (1971) finding that those with need for growth in their jobs preferred work that provided variety, autonomy and feedback. Accordingly, growth oriented individuals tend to increase TP in more empowered HR cultures or less business driven HR cultures.

\subsection{2: Performance Management Practices as a Moderator}

There are two major findings in relation to the moderating impact of HRM culture concerned with performance management practices. The first finding indicates that the employees with an extrinsic value orientation tend to reduce negative outcomes in relation to $\mathrm{CPTO}(\beta=.07 ; \mathrm{P}<.05 ; \mathrm{r}=-.01)$, and how to produce positive outcomes in relations to CPTIR $(\beta=.15 ; \mathrm{P}<.001 ; \mathrm{r}=.07)$ in an environment where a career and promotion system based on performance and formalized evaluation is adopted. This seems to reflect the fact that extrinsic values oriented people tend to show their desire not only through monetary and material rewards as explained in the theory, but also by being involved in contextual performance activities in an environment of performance based rewards system is adopted. The second finding indicates that the employees with individual growth oriented work norms tend to produce positive outcomes in relation to CPTIR $(\beta=.13 ; \mathrm{P}<.05 ; \mathrm{r}=.16)$ and TP $(\beta=.25 ; \mathrm{P}<.001 ; \mathrm{r}=$ .18) in an HRM culture where a career and promotion system based on performance and formalized evaluation is adopted. This seems to indicate that individual growth oriented people seem to be more dynamic as far as CTP is concerned. For example, in the previous section it was indicated that employees with individual growth oriented work norms tend to produce positive TP in an environment of more empowering HRM culture.

In this section it indicates that they tend to produce positive TP and CPTIR outcomes in an environment where a career and promotion system based on performance and formalized evaluation is adopted. In summary, this seems reflect the fact that employees with individual growth oriented work norms tend to achieve their growth needs by responding eagerly and positively to the opportunities provided by enriched work (e.g. Hackman and Walton (1986), while expecting their performance being evaluated formally and considered in promotion for improving CTP.

\subsection{3: Diverse Functional Perspective of Job-Person fit as a Moderator}

The moderating impact of the functional perspective of job-person fiton the relationship between WEV and CTP indicate the following. First, it indicates that the employees with individual growth oriented work norms tend to produce positive outcomes in relation to $\mathrm{CPTO}(\beta=.08 ; \mathrm{P}<.05 ; \mathrm{r}=.19), \mathrm{CPTIR}(\beta=.08 ; \mathrm{P}<.05 ; \mathrm{r}=.15)$, and TP $(\beta=.17 ; \mathrm{P}<.001 ; \mathrm{r}=.21)$ in an environment where diverse functional perspective on job-person fit is considered. This finding is consistent not only with the findings of this study as explained in the previous section, but also with the Hackman and Lawler (1971) finding that those with need for growth in their jobs prefer work that 
provides variety, autonomy and feedback. In addition, Yeatts and Hyten (1998) also note that characteristics associated with the growth need include a need for self-direction, learning, personal accomplishment, and development beyond where one is now. Second, employees with extrinsic work value orientations tend to produce positive performance outcomes in relation to $\mathrm{CPTO}(\beta=.04 ; \mathrm{P}<.05 ; \mathrm{r}=-.13)$ and $\mathrm{TP}(\beta=.04 ; \mathrm{P}<.05 ; \mathrm{r}=-.10)$ in an HRM culture where less diverse functional perspective on job-person fit is adopted. This finding is consistent with some other findings of this study as explained in the previous section. They both indicated that extrinsic value oriented people desire not only monetary and material rewards, but also tend to be involved in CTP in an environment where performance-based rewards system is adopted. This finding adds another point to the list of environmental characteristics for extrinsic value oriented people as they also prefer less diverse HRM cultures in order to be productive in $\mathrm{CPTO}$ and $\mathrm{TP}$.

Finally, it is found that the employees with intrinsic work value orientations tend to produce negative performance outcomes in relation to CPTIR $(\beta=-.08 ; \mathrm{P}<.05 ; \mathrm{r}=-.08)$ in an environment where less diverse functional perspective on job-person fit is adopted. This is a very interesting finding as far as the characteristics of intrinsically value-oriented people are concerned. Theoretically, intrinsic values include autonomy, variety, an interesting job, learning new things, using skills and abilities, challenge, and innovation (Wang, 1996). Thus, it is obvious that intrinsic value oriented people tend to produce negative CTP outcomes in an environment where less diverse functional perspective on job-person fit is adopted.

\section{Conclusions and Implications}

There were two major objectives of this study: examination of direct impact, and moderator impact of WEV on CTP. The findings in relation to direct impact indicated that both demographic and MVWO variables influenced CTP. Among the demographic factors, gender, employment category, and the level of education all had significant impact on CP. The WEV variable of intrinsic values has a positive impact on all the three criteria of CTP. In addition, CPTIR and TP were positively influenced by the individuals with growth oriented work norms and the career oriented work ethics and negatively influenced by the external work locus of control. There are several implications of these findings. Firstly, HR managers may consider employees' work ethics and values when they select people for positions that require more CTP activities. Secondly, HR managers may also include positive work values in their training and development programs in order to modify the existing behaviors so that they expect a relatively high CTP. Finally, as Paine and Organ (2000) indicate, the unique human resource values and preferences for HRM practices could be considered as sources that create competitive advantages (e.g. Kidder, 2002). Theoretically, several scholars have stressed the need for identifying not only individual difference attributes of OCB, but also their direct and interactive impact on performance outcomes (e.g. Mao et al., 2013; Triguero et al., 2013; Husin et al., 2012; Ilieset a.,2006). The evidence of this study contributes to fill that knowledge gap to some extent. This evidence also confirms the Taris and Feij' (2001) argument that the direct effect of employee's work values will be smaller or even absent since the question of whether or not a particular value has an effect, seems to depend on the work environment they desire to work or actually work.

On the other hand, all the three HRM cultures found in this study can be considered as examples of effective moderators of WEV orientations on CTP. The discovery of a significant moderator can yield new inferences and conclusions and thereby enhances not only the generalizability of work value research (e.g. Sagie et al., 1996), but also new directions for exploring dynamic impact of preferences for HRM practices in future research. This study has a number of limitations such as sample size, manufacturing sector focus, a single country, a limited number of work values variables, a cross-sectional study etc., which warrant further studies of integrative research. Finally, we conclude that unique human resource values, HRM policy-practice design choices and their interactive effect could be considered as sources that enhance performance at work and create competitive advantages.

\section{References}

Aiken, L. S., \& West, S. G. (1991). Multiple regression: Testing and interpreting interactions. Thousand Oaks, CA: Sage.

Baron, R.M. and Kenny, D.A. (1986). The moderator-mediator variable distinction in social psychological research: conceptual, strategic, and statistical considerations, Journal of Personality and Social Psychology, 51(6):1173-1182. 
Borman, W.C. and Motowidlo, S.J. (1997). Task and contextual performance: the meaning for personnel selection research, Human Performance, 10(2): 99-109.

Borman, W.C., Penner, L.A., Allen, T.D. and Motowidlo, S.J. (2001). Personality predictors of citizenship performance, International Journal of Selection and Assessment, 9 (1/2): 52-69.

Buchholz, R.A. (1977). The belief structure of managers relative to work concepts measured by a factor analytic model, Personnel Psychology, 30: (567-587).

Chandrakumara, A. Sparrow, P.(2004). Exploring Meaning and Values of Work Orientation as an Element of National Culture and Its Impact on HRM Policy-Practice Design Choices, International Journal of Manpower, Vol.25 No.6.pp.364-389.

Claes, R. and Ruiz-Quintanilla, S.A.(1995). Work meaning patterns in early career. In J.M. Peiro., B. F. Prieto., J.L. Melia and O.Luque (Eds.) Work and Organizational Psychology: European contribution of the Nineties, UK: Erlbaum (UK) Taylor \& Francis.

Cohen, A. (1992). Antecedents of organizational commitment across occupational groups: a meta-analysis, Journal of OrganizationalBehavior, 13: 539-558.

Costa, P.T., Jr., McRae, R.R. and Holland, J.L.(1984). Personality and Vocational Interest in an adult sample, Journal of Applied Psychology, 69: 390-400.

Denison, D.R. (1996). What is the difference between organizational culture and organizational climate? A native's point of view on a decade of paradigm wars, Academy of Management Review, 21: 619-654.

Dickson, J.W. and Buchholz, R.A. (1977). Managerial Beliefs about work in Scotland and the U.S.A., Journal of Management Studies, 14: 80-101.

Dose, J. J. (1997). Work Values: An integrative framework and illustrative application to organizationalsocialization, Journal of Occupational and Organizational Psychology, 70, 219-240.

England, J.W. and Harpaz, I. (1990). How work is defined: National contexts and demographic and organizational role influences? Journal of Organizational Behavior, 11, 253-266.

England, G.W. \& Lee, R. (1974). The relationship between managerial values and managerial success in the United States, Japan, India and Australia, Journal of Applied Psychology, 59: 411-419.

Erez, F. \&Earley, P. C. (1993).Culture, Self-Identityand Work. New York: Oxfords University Press.

Farh, J.L., Earley, P.C., \& Chi Lin, S. (1997). Impetus for action: A cultural Analysis of justice and Organizational citizenship behavior in Chinese society,Administrative Science Quarterly, 42: 421-444.

Finegan, J.E. (1994). The impact of personal values on judgements of ethical behavior in the workplace, Journal of Business Ethics, 13: 747-755.

Furnham, A. (1997). The psychology of behavior at work: the individual in the organization, UK: Psychology Press.

Goodman, S.A. and Svyantek, D.J. (1999). Person-organization fit and contextual performance: Do shared values matter? Journal of Vocational Behavior, 55: 254-275.

Hackman, J.R., and Walton, R.E. (1986).Leading groups in organizations. In P.S. Goodman (Ed.) Designing Effective Work Groups (pp.72-119), San Francisco: Jossey-Bass.

Hackman, J.R., \& Lawler, E.E. 1ll. (1971). Employee reactions to job characteristics, Journal of Applied Psychology Monograph, 55(3): 259-286.

Hui, C. and Lee, C. (2000). Moderating effect of organization based self-esteem on organizational uncertainty: employee response relationships, Journal of Management, 26(2): 215-232.

Huseman, R.C., Hatfield, J.D. and Miles, E.W. (1987). A new Perspective on Equity theory, Academy of Management Review, 12(2): 222-234.

Husin, S., Chelladurai, P., and Musa, G. (2012). HRM practices, Organizational Citizenship behavior and perceived service quality in golf courses, Journal of Sport Management, Vol. 26, pp.143-158.

James L.R. and Brett, J.M. (1984). Mediators, moderators, and test for mediation, Journal of Applied Psychology, 69(2): 307-321.

Kazanas, H.C. (1978). Relationship of job satisfaction and productivity to work values of vocational education graduates, Journal of Vocational behavior, 12(2): 155-164.

Koslowsky, M. (1996). Work values: a theoretical overview and a model of their effects, Journal of OrganizationalBehavior, 17: 503-514.

Kluckhohn, F.R.andStrodbeck, F.L. (1961). Variations in value orientations, New York: Harper \& Row. 
Lee, K.Y. and Kim, S.(2010). The effect of commitment based human resource management on organizational citizenship behaviors: The mediating role of psychological contacts, World Journal of Management, Vol.2, pp.130-147.

Ilies, R., Scott, B.A., and Judge, T.A. (2006).A Multilevel analysis of the effects of positive personal traits, Positive experienced status, and their interaction on intra-individual patterns of citizenship behavior at work, Academy of Management, 49(3), 561-575.

Mao, N., Song, H. and Han, Y. (2013). High-performance work systems and influence processes on employees' attitudes", International Journal of Manpower, Vol.34 No.7, pp. 736-752.

Meglino, B.M., Ravlin, E.C. and Adkins, C.L. (1989). A work value approach to corporate culture: A field test of the value congruence process and its relationship to individual outcomes, Journal of Applied psychology, 74(3): 424-432.

Mendonca, M. and Kanungo, N.K. (1990).Performance Management in Developing Countries.In Jaeger, A.M. and Kanungo, R.N. (Eds.) Management in Developing Countries, London: Logman.

Merrens, M.R. and Garrett, J.B. (1975).The Protestant ethic scale as a predictor of repetitive work performance, Journal of Applied Psychology, 60(1): 125-127.

Motowidlo, S.J. and Van Scotter, J.R. (1994).Evidence that task performance should be distinguished from contextual performance, Journal of Applied Psychology, 79(4), 475-480.

Mottaz, C. (1986). Gender differences in work satisfaction, work-related rewards and values, and the determinants of work satisfaction, Human Relations, 39(4): 359-377.

MOW International Research Team (1987).The meaning of working, London: academic Press.

Nyambegera, S.M., Sparrow, P.R. and Daniels, K. (2000). The impact of cultural value orientations on individual HRM preferences in developing countries: lessons from Kenyan organizations. International Journal of Human Resource Management, 11(4): 639-663.

Nyambegera, S.M., Daniels, K and Sparrow, P.R. (2001). Why fit doesn't always matter: The impact of HRM and cultural fit on job involvement of Kenyan employees, Applied Psychology: An International Review, 50(1): 109-140.

Olsen, J.E (2013). Societal values and individual values in reward allocation preferences, Cross Cultural Management, 22(1), 187-200 [Online] Available: https://doi,org/10.1108.CCM-09-2013-0130. (August $16,2018)$.

Paine, J.B. and Organ, D.W. (2000).The cultural matrix of organizational citizenship behavior: some preliminary conceptual and empirical observations, HumanResources Management Review, 10(1): 45-59.

Pierce, J.L., Gardner, D.G., Dunham, R.B. \& Cummings, L.L. (1993). Moderation by organization-based selfesteem of role condition-employee response relationships, Academy of Management Journal, 36: 271288.

Podsakoff, P.M., MacKenzie, S.B., Paine, J.B., \&Bachrach, D.D. (2000).Organizational citizenship behavior: Critical review of the theoretical and empirical literature and suggestions for future research, Journal of Management, 26(3): 513-563.

Reitz, H. J. and Jewell, L.N. (1979). Sex, locus of control, and job involvement: A six-country investigation Academy of Management Journal, 22: 72-80.

Putti, J.M., Aryee, S., \& Liang, T.K. (1989). Work values and organizational commitments: A study in the Asian context, Human Relations, 42: 275-288.

Rokeach, M. (1973).The Nature of Human Values, New York: Free Press.

Roe, R.A. and Ester, P. (1999). Values and Work: Empirical findings and theoretical perspectives, Applied Psychology: An International Review, 48(1): 1-21.

Ros, M., Schwartz, S.H., and Surkiss, S. (1999). Basic Individual Values, Work Values, and the Meaning of Work, Applied Psychology: An International Review, 48(1): 49-71.

Ruiz-Quintanilla, S.A. and England, G.W. (1996). How working is defined?: Structure and stability, Journal of OrganizationalBehavior, 17: 515-540.

Sagie, A., Elizur, D. and Koslowsky, M. (1996). Work values: a theoretical overview and a model of their effects, Journal of OrganizationalBehavior, 17: 503-514.

Saufi, M.A., Kojuri, M.A.S., Badi, M., and Agheshlouei, H.(2013). Impact of organisational justice and psychological empowerment on OCB: The mediating effect of job involvement, International Journal of research in Organisational Behaviour and HRM, Vol.1 No.3, pp. 116-135. 
Shapira, Z. \& Griffith, T.L. (1990).Comparing the work values of engineers with managers, production, and clerical workers: A multivariate analysis, Journal of OrganizationalBehavior, 11: 281-292.

Schuler, R.S., and Jackson, S.E.(2014). Human Resource Management and Organizational Effectiveness: Yesterday and Today, Journal of Organizational Effectiveness: People and Performance,Vol.1 No.1, pp.35-55.

Schuler, R. S. and Jackson, S.E. (1987).Linking Competitive Strategy with HRM Practices, Academy of Management Executive, 1(3): 207-219.

Smith, C.A., Organ, D.W. and Near, J.P. (1983).Organizational citizenship behavior: its nature and antecedents, Journal of Applied Psychology, 68(4): 653-663.

Snape, E. and Redman, T.(2010). HRM Practices, Organizational Citizenship Behavior, and Performance”, Journal of Management Studies, Vol.47 No.7, pp.1219-1247.

Smith, C.A., Organ, D.W. and Near, J.P. (1983).Organizational citizenship behavior: its nature and antecedents, Journal of Applied Psychology, 68(4): 653-663.

Sparrow, P. R., Chandrakumara, A. \& Perera, N. (2010). Impact of work values and ethics on citizenship and task performance in local and foreign invested firms: A test in a developing country context. 11th International Human Resource Management Conference (pp.1-25). Birmingham, UK: Aston Business School.

Sparrow, P.R. and Wu, P. (1998). How much do National Value orientation Really Matter? Predicting HRM preferences of Taiwanese Employees, Employee Relations, 20(1): 26-56.

Spector, P. (1982). Behavior in organizations as a function of employees' locus of control, Psychological Bulletin, 91: 482-497.

Taris, R., and Feij, J.A. (2001). Longitudinal Examination of the relationship between Supplies-Values fit and work outcomes, Applied Psychology: International Review, 50(1): 52-80.

Triguero-Sanchez, R., Pena-Vinces, J.C. and Sanchez-Apellaniz, M. (2013). Hierarchical distance as a moderator of HRM practices on organizational performance, International Journal of Manpower, Vol.34 No.7, pp.794-812

Warren, C; McGraw, A.P; and Boven, L.V. (2011). Values and preferences: Defining preference construction, Advanced Review, 2, March/April 2011, John Wiley \& Sons Ltd.

Weick, K.E. (1996). 'Enactment in the boundaryless career: organizing as we work', In M.B. Arthur \& D.M. Rousseau (Eds.) The Boundaryless Career: A new Employment Principle for a New Organizational Era (pp. 109-159), New York: Oxford University Press.

Wollack, S., Goodale, J.G., Wijting, J.P. and Smith, P.C. (1971). Development of Survey of Work Values, Journal of Applied Psychology, 55(40 331-338.

Yeatts, D.E and Hyten, C. (1998).High-Performance Self-managed Work teams, A comparison of theory and Practice, London, Sage publication 